\title{
Management of a patient with a large airway stent in situ
}

\author{
Simon Parrington, MBBS · Paul Tumber, MD • \\ David Wong, MD
}

Received: 20 April 2009/Accepted: 15 June 2009/Published online: 27 June 2009

(C) Canadian Anesthesiologists' Society 2009

\section{To the Editor,}

Bronchial stents are being placed more frequently for a diverse range of benign and malignant conditions. These patients may require non-pulmonary surgery and as a part of their preoperative assessment, consideration for displaced stents should be included in the planned airway management technique. We describe the case of a 55-yrold male who was scheduled for elective laparoscopic repair of a recurrent inguinal hernia. The patient's medical history included a 30-pack year smoking history, recurrent purulent pneumonia, and bronchiectasis. He denied any current respiratory symptoms. Eleven years earlier, the patient underwent a rigid bronchoscopy which demonstrated a proximal left main bronchus stenosis secondary to chronic lingular adenopathy. Flexible bronchoscopy was performed, and two bare metal stents were deployed at the opening and in the proximal portion of the left mainstem bronchus. The patient did not return for follow-up of his bronchial stents. His physical examination was unremarkable, except for a few scattered crackles bibasally in his lung fields. A chest radiograph (Fig. 1) showed that the proximal stent appeared to be positioned at the opening of the left main bronchus and the distal stent at an angle of $30^{\circ}$ to the first with some bibasal atelectasis. A lateral chest film demonstrated good antero-posterior alignment of the two stents.

Because of the long duration between follow-up and the propensity for metallic stent migration and granulation tissue overgrowth, it was decided to proceed cautiously

\footnotetext{
S. Parrington, MBBS $(\bowtie) \cdot$ P. Tumber, MD $\cdot$ D. Wong, MD

Toronto Western Hospital, University of Toronto,

Toronto, Canada

e-mail: Simon.Parrington@uhn.on.ca; parringtonfamily@

googlemail.com
}

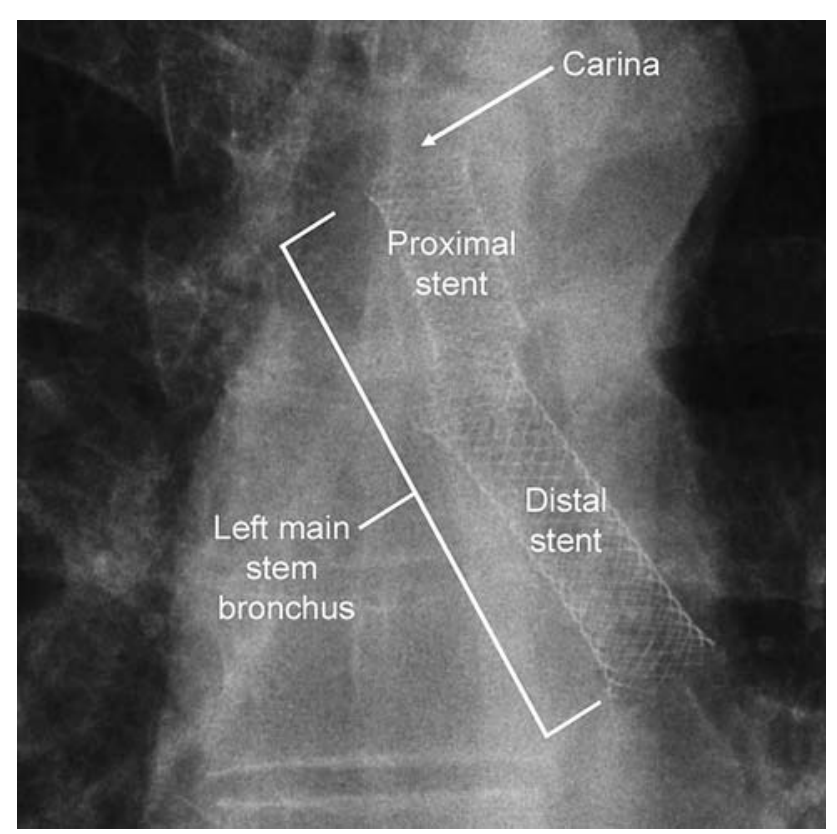

Fig. 1 Magnified postero-anterior (PA) chest radiograph showing left mainstem bronchial stents

with flexible fibreoptic bronchoscopy. Following induction of anesthesia and confirmation of easy ventilation, endoscopic examination of the tracheo-bronchial tree demonstrated a proximally migrated stent with soft tissue overgrowth (Fig. 2). A size 7.5 cuffed tracheal tube was mounted on an intubating fibrescope and carefully advanced into position above the carina; bilateral chest ventilation was confirmed. Following uneventful surgery, a repeat endoscopic examination and chest X-ray revealed no movement of the stent or residual pneumothorax. The patient was referred to his respiratory physician for replacement of his bronchial stent. 


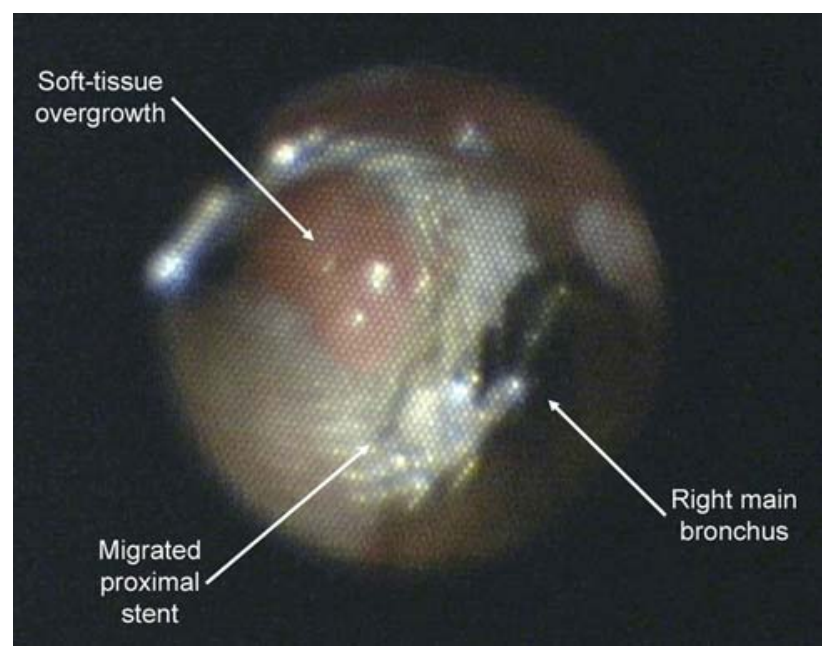

Fig. 2 Endoscopic view at the level of the carina showing a proximally migrated stent with soft tissue overgrowth

Fractured or displaced stents can cause problems due to migration, stent fracture, or granulation tissue overgrowth. The severity of these problems ranges from mild, such as halitosis, to potentially catastrophic, causing pneumothorax, lobar collapse, distal infection, and erosion or rupture of the great vessels of the chest. ${ }^{1}$ For patients with large airway stents in situ presenting for surgery, anesthesiologists should perform a thorough history and physical examination and obtain past records and diagnostic images. A supraglottic device is preferable in patients presenting for elective surgery where there is little risk of aspiration or no need for tracheal intubation, as it reduces the likelihood of stent displacement. If the stent is fractured, misplaced, or associated with respiratory symptoms, then consideration should be given to seeking a thoracic consultation prior to elective surgery. If tracheal intubation is necessary, careful flexible bronchoscopy should be performed to assess the integrity and position of the stent and to optimally position the tracheal tube tip in relation to the stent prior to surgery. ${ }^{2}$

Improvements in technology and experience in their use are leading to an increasing number of patients being treated with large airway stents.

Anesthesiologists in specialist and non-specialist centres are more likely to encounter these patients and should understand how to manage such patients for elective and emergency surgery without compromising stent integrity.

Competing interests None declared.

\section{References}

1. Asopa S, Moorjani N, Saad RA, Turner JT, Amer KM. Rare and fatal complication of gianturco tracheobronchial stent. Ann Thorac Surg 2007; 84: 1758-60.

2. Davis N, Madden BP, Sheth A, Crerar-Gilbert AJ. Airway management of patients with tracheobronchial stents. Br J Anaesth 2006; 96: 132-5. 